\title{
Sitting proudly atop the all American (?) bandwagon
}

Philip Morris exploits American imagery in cigarette promotions worldwide. Curiously, tobacco multinationals from other countries employ precisely the same tactic. British American Tobacco (BAT), for example, promotes Lucky Strike as "an American original", rather than "a British acquisition".

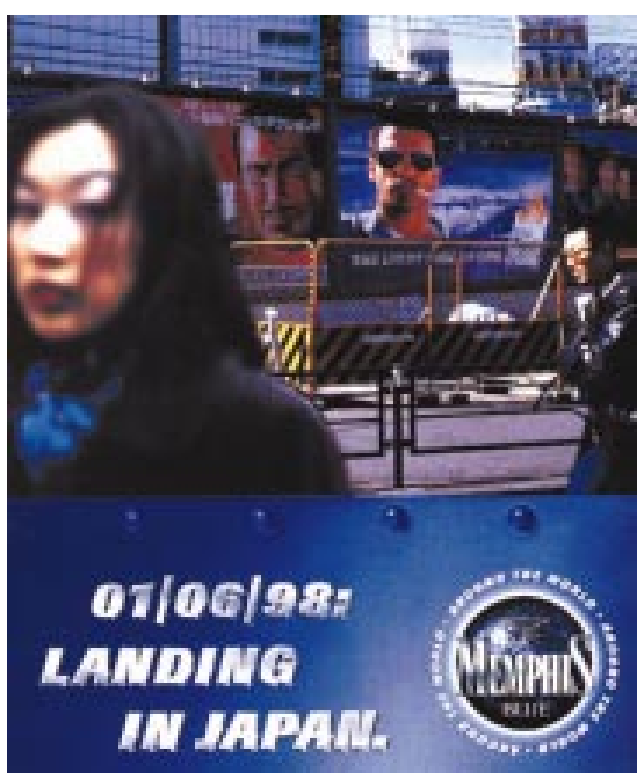

This ad, from a popular Austrian magazine (Wiener, April 1999), depicts the 1998 launch in Japan of Austria Tabak's leading brand. Neither the billboard nor the magazine ad contains a single word of Japanese or German. Then there is the pilot, with his Tom Cruise approved sunglasses. Could any Japanese passerby look at this billboard and figure out that Memphis is a product of Austria, not the USA?

During the Kosovo conflict, the citizens of neutral Austria were relieved that they bore no responsibility for civilian casualties of NATO bombing raids. Do they not also wish to distance themselves from the bombardment of other countries with addictive, toxic consumer products? Apparently Austria Tabak assumes its domestic audience will not question the ethics of tobacco marketing abroad. Otherwise the company would keep quiet about its "landing in Japan".

Philip Morris shows little restraint in its own overseas marketing. But it is hard to imagine the company paying for ads at home to brief US citizens on its actions abroad.

sthompson5@home.com

SCOTT THOMPSON

PO Box 141

San Clemente, $C A 92674$

USA

Fax: +603.947 .7510$ 